\title{
Chaotropic Agents Boosting the Performance of Photoionic Cells
}

\author{
Romain Bourdon, ${ }^{\dagger}$ Pekka Peljo, ${ }^{\dagger}$ Manuel A. Méndez, ${ }^{\dagger}$ Astrid J. Olaya, ${ }^{\dagger}$ Jelissa De Jonghe-Risse, ${ }^{\ddagger}$ \\ Heron Vrubel, ${ }^{\dagger}$ and Hubert H. Girault* ${ }^{\dagger}$ \\ ${ }^{\dagger}$ Laboratoire d’Electrochimie Physique et Analytique and ${ }^{\ddagger}$ Groupe de Dynamique Photochimique, Ecole Polytechnique Fédérale de \\ Lausanne, CH-1015 Lausanne, Switzerland
}

\section{Supporting Information}

ABSTRACT: Photoionic cells are a simple and scalable concept for direct solar energy storage, where the redox fuels produced by the photoreaction are separated in different phases to prevent recombination. The presence of chaotropic agents such as urea, that break the structure of water, was found to drastically enhance the quantum yield; a 10-fold increase of quantum yield to over $13 \%$ was achieved by addition of chaotropes into a system based on the reductive quenching of Azure B by Co(II)EDTA in water and the extraction of the leuco dye in 1,2-dichloroethane.

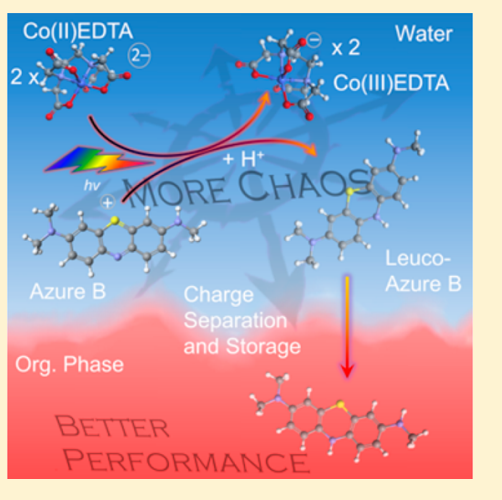

\section{INTRODUCTION}

Solar energy conversion is one of the global challenges for a sustainable economy. At present, two major routes are being followed: photovoltaic (PV) systems to generate electricity and solar thermal collectors to generate heat. However, all PV technologies must immediately distribute the produced electricity either to a storage system or to the electrical grid, irrespective of demand. Recently, we have proposed a simple and scalable concept for solar energy storage: photoionic cells. ${ }^{1}$ This is an extension of the early work of Rabinowitch et al. ${ }^{2-5}$ and Albery et al. ${ }^{6-9}$ on photogalvanic cells (essentially photochemical concentration cells), but in photoionic cells the charge separation takes place at the interface between two immiscible electrolyte solutions. ${ }^{1}$ The system is based on a dye-quencher couple where, upon light excitation, the excited dye (for example thionine) is quenched in the aqueous solution by the quencher (e.g., $[\mathrm{Co}(\mathrm{II}) \mathrm{EDTA}]^{2-}$ ) to form both an oxidized quencher (e.g., $[\mathrm{Co}(\mathrm{III}) \mathrm{EDTA}]^{-}$) and reduced neutral dye (leucothionine) that partitions to the organic phase. The two immiscible liquid phases are separated, and the redox energy is stored in the respective electrolyte solutions. These two solutions can then be electrochemically discharged in a flow cell to generate electricity on demand. The main potential advantage of photoionic cells over classical solar cells is the unique ability to convert solar energy directly into "redox fuels" that can be consumed only when electricity is required to generate electricity to meet a specific demand.

The original thionine-cobalt EDTA system $^{1}$ has some drawbacks, like low potential difference between the two photogenerated redox couples and very low solubility of thionine, which limits the quantum yield of the system. Another serious issue that has to be considered is dye aggregation, leading to significant loss of performance. In order to overcome such drawbacks, in this work we have explored Azure B $\left(\mathrm{H}_{2} \mathrm{AzB}\right)$ as an interesting alternative in the development of systems capable of capturing, converting, and storing solar energy in the form of reduced and oxidized photoproducts separated by a polarized interface formed between two immiscible electrolyte solutions.

We have systematically studied the effects of the physicochemical and photophysical properties of a dye on the quantum yield, and we have optimized the reaction conditions in the photoionic cells in order to maximize the quantum yield of the reaction. More importantly, we have shown that by increasing disorder in the solvent by introduction of chaotropic agents like urea (also known as structure breakers) the quantum yield was increased by an order of magnitude to $13.1 \%$ for conversion of photons into photoproducts.

\section{EXPERIMENTAL SECTION}

Chemicals. All aqueous solutions were prepared with ultrapure water (Millipore Milli-Q, specific resistivity 18.2 $\mathrm{M} \Omega . \mathrm{cm}$ ). Azure B chloride ( $\mathrm{HAzBCl}$, prepared by direct synthesis) and tetrahexylammonium tetrafluoroborate $\left(\mathrm{THxABF}_{4}, \geq 97.0 \%\right)$ were purchased from Aldrich. Tetrahexylammonium chloride (THxACl, $\geq 96.0 \%$ ), tetramethylammonium chloride (TMACl, $\geq 98.0 \%$ ), 1,2-dichloroethane (DCE, $\geq 99.8 \%$ ), anhydrous lithium chloride ( $\geq 99.0 \%)$, and urea $(\geq 99.5 \%)$ were ordered from Fluka. They were used as received except urea, which was recrystallized from absolute

Received: January 12, 2015

Revised: February 10, 2015

Published: February 13, 2015 
ethanol (Fluka, $\geq 99.8 \%$ ) in order to avoid electroactive impurities. Potassium cobalt(III) EDTA (K[Co(III)EDTA]) was synthesized according to the method described by Dwyer et al., ${ }^{10}$ whereas the following modification was used for the synthesis of $\mathrm{K}_{2}$ [Co(II)EDTA]: cobalt(II) acetate (Aldrich, $\geq 99.995 \%), N$-(2-hydroxyethyl) ethylenediamine- $N, N^{\prime}, N^{\prime}$-triacetic acid $\left(\mathrm{H}_{4} \mathrm{EDTA}\right.$, Aldrich, $\left.\geq 98.0 \%\right)$, and potassium acetate (Aldrich, $\geq 99.0 \%)$ were mixed up (1:1:2). Solid $\mathrm{K}_{2}[\mathrm{Co}(\mathrm{II})$ EDTA] was precipitated out of the solution by addition of ethanol, filtered by suction, washed with diethyl ether (Aldrich, $\geq 98.0 \%$ ) and dried under vacuum. Lithium tetrakis(pentafluorophenyl)borate (LiTB) n-etherate (Boulder Scientific) and bis(triphenylphosphoranylidene) ammonium chloride (BACl, Aldrich, $\geq 97.0 \%$ ) were used to prepare bis(triphenylylphosphoranylidene) ammonium tetrakis(pentafluorophenyl)borate (BATB) by metathesis of aqueous equimolar solutions of $\mathrm{BACl}$ and $\mathrm{LiTB}$. The resulting precipitates were filtered, washed, and recrystallized from an acetone:ethanol (1:1) mixture. ${ }^{11}$ Leuco-Azure B $\left(\mathrm{H}_{2} \mathrm{AzB}\right)$ was synthesized via a potential-controlled bulk electrolysis at -0.55 $\mathrm{V}$ vs $\mathrm{Ag} / \mathrm{AgCl}(3 \mathrm{M} \mathrm{KCl})$ at $\mathrm{pH} 8.0$ in an $\mathrm{H}$-Cell with two high surface area vitreous carbon electrodes from a solution of Azure $B$ in a $20 \mathrm{mM}$ Tris buffer.

Mixtures of citric acid (Fluka, $\geq 99.5 \%$ ) and trisodium citrate dihydrate (Fluka, $\geq 99.0 \%$ ) were used for imposing the $\mathrm{pH}$ values 6.0 and 6.5. For a $\mathrm{pH}$ range from 7.5 to 9.0, tris(hydroxymethyl)aminomethane (Tris, Acros Organics, $\geq 99.8 \%$ ) was used with hydrochloric acid (Acros Organics, $32 \%$ solution in water) for $\mathrm{pH}$ adjustments. Sodium hydroxide (Fluka, $\geq 97.0 \%$ ) was used to reach higher $\mathrm{pH}$ values. Orthophosphoric acid (Fluka, $85.0 \%$ solution in water) was used in a mixture of acids for the Pourbaix diagram.

Electrochemical Measurements. Ion-transfer voltammetry experiments at the water-DCE interface (area of ca. 1.54 $\mathrm{cm}^{2}$ ) in a four-electrode configuration and classical voltammetry with a three-electrode configuration were all performed using a PGSTAT 30 potentiostat (Metrohm, CH). In the fourelectrode configuration, two platinum counter electrodes were positioned in the aqueous and organic phases, respectively, to supply the current flow. Silver/silver chloride reference electrodes were connected to the aqueous and organic phases, respectively, via Luggin capillaries. The Galvani potential difference across the interface $\left(\Delta_{\mathrm{o}}{ }^{\mathrm{w}} \phi\right)$ was estimated by taking the standard ion transfer potential of the tetramethylammonium cation $\left(\mathrm{TMA}^{+}\right)$as $0.160 \mathrm{~V} .^{12}$ The half-wave potential of $\mathrm{TMA}^{+}$was estimated as $0.13 \mathrm{~V}$ based on correction of ionic activities by Debye-Hückel theory as described by Wandlowski et al. ${ }^{12}$

To determine the redox potential and the diffusion coefficient of Azure B, cyclic voltammetry and chronoamperometry measurements were carried out with a three-electrode configuration (WE: glassy carbon electrode; CE: platinum wire; ref: $\mathrm{Ag} / \mathrm{AgCl}$ electrode) in a solution of Azure B $(75 \mu \mathrm{M})$ at $\mathrm{pH} 8.0$ (Tris Buffer, $20 \mathrm{mM}$ ) and lithium chloride $(50 \mathrm{mM})$ as supporting electrolyte. For the determination of the Pourbaix diagram, a classical three-electrode configuration (WE: platinum electrode; $\mathrm{CE}$ : platinum wire; ref: $\mathrm{Ag} / \mathrm{AgCl}$ electrode $(3 \mathrm{M} \mathrm{KCl})$ ) was used in a $10 \mathrm{~mL}$ aqueous solution consisting of phosphoric acid $(15 \mathrm{mM})$, hydrochloric acid $(70 \mathrm{mM})$, acetic acid $(15 \mathrm{mM})$, and $\mathrm{HAzBCl}(50 \mu \mathrm{M})$. Cyclic voltammograms were recorded at each addition of $25 \mu \mathrm{L}$ of $\mathrm{NaOH}(1.5 \mathrm{M})$.

Spectroscopic Measurements. An Agilent 8452 spectrophotometer was used with quartz cells of $1 \mathrm{~cm}$ for diluted solutions (from 1 to $50 \mu \mathrm{M}$ ), $0.5 \mathrm{~cm}$ (for solutions from 60 to $100 \mu \mathrm{M}$ ), and $0.1 \mathrm{~cm}$ (for solutions $>100 \mu \mathrm{M}$ ) path lengths. For quantum yield estimation, all spectroscopic measurements were performed in a nitrogen-filled glovebox. An Ocean Optics spectrophotometer was used together with halogen and deuterium lamps as light sources. A quartz cell of $1 \mathrm{~cm}$ path length with equal amounts of aqueous and organic phases under stirring was irradiated with a laser at $632.8 \mathrm{~nm}$ for a certain amount of time, and the amount of reduced dye was evaluated immediately from the change in the absorbance of Azure B.

The partition coefficient of the reduced Azure B was determined by evaluating the change in the absorbance of the leucodye synthesized by bulk electrolysis in the aqueous phase after equilibration with an equal amount of DCE phase. ${ }^{1}$

Transient Absorption Spectroscopy. Transmissionmode transient absorption experiments were carried out using a frequency-tripled Q-switched Nd:YAG laser (Ekspla NT-342) running at $20 \mathrm{~Hz}$ repetition rate. The excitation wavelength set at $644 \mathrm{~nm}$ was generated by an optical parametric oscillator (5 $\mathrm{ns}$ fwhm) and attenuated by gray filters to yield about $220 \mu \mathrm{J} /$ $\mathrm{cm}^{2}$ at the sample solution ( $1 \mathrm{~cm}$ quartz cell). The continuouswave probe light from a xenon lamp was passed through various optical elements, the sample, and a monochromator before being detected by a fast photomultiplier tube (R928 Hamamatsu) and recorded by a digital oscilloscope (Tektronix DPO 7104C). Averaging was done over 3000 laser shots for a satisfactory signal-to-noise ratio, with dynamics recorded over 10000 points. The solution was prepared in the glovebox and maintained in a $\mathrm{N}_{2}$ atmosphere during the measurements.

Flow Conditions. The DCE phase and aqueous phase were placed in a reaction vessel under nitrogen atmosphere (Figure 1). The aqueous solution was drawn out of the reaction vessel,

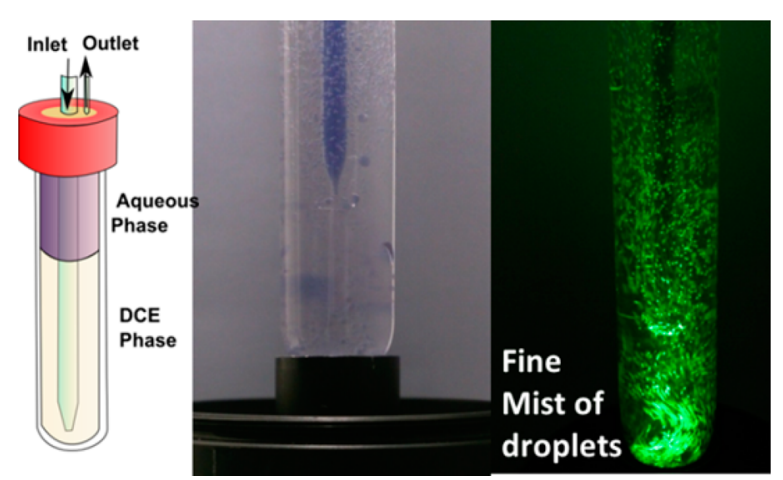

Figure 1. Flow reactor for charging of the photoionic cell, where the aqueous phase is continuously pumped through an UV-vis flow cell into the DCE phase through a fine capillary, generating a fine mist of droplets slowly floating up. The reactor is illuminated from below.

passed through a UV-vis flow cell, and reinjected into the transparent vessel through a capillary inside the DCE phase, creating a fine mist of aqueous droplets containing the dye and quencher. The reactor vessel was irradiated from below with the LED light (Thorlabs, $1234 \mathrm{~W} \mathrm{~m}^{-2}$ at $625 \mathrm{~nm}$ ). This allowed the monitoring of the photoreaction in situ.

\section{RESULTS AND DISCUSSION}

Spectroscopic Characterization. The solubility of the dye is critical to the photoionic cell performance, ${ }^{1}$ so to understand the behavior of Azure B in the solution, UV-visible spectra of 
$\mathrm{HAzB}^{+}$were acquired at various concentrations (Figure 2). The absorbance at $646 \mathrm{~nm}(1.92 \mathrm{eV})$ attributed to monomeric
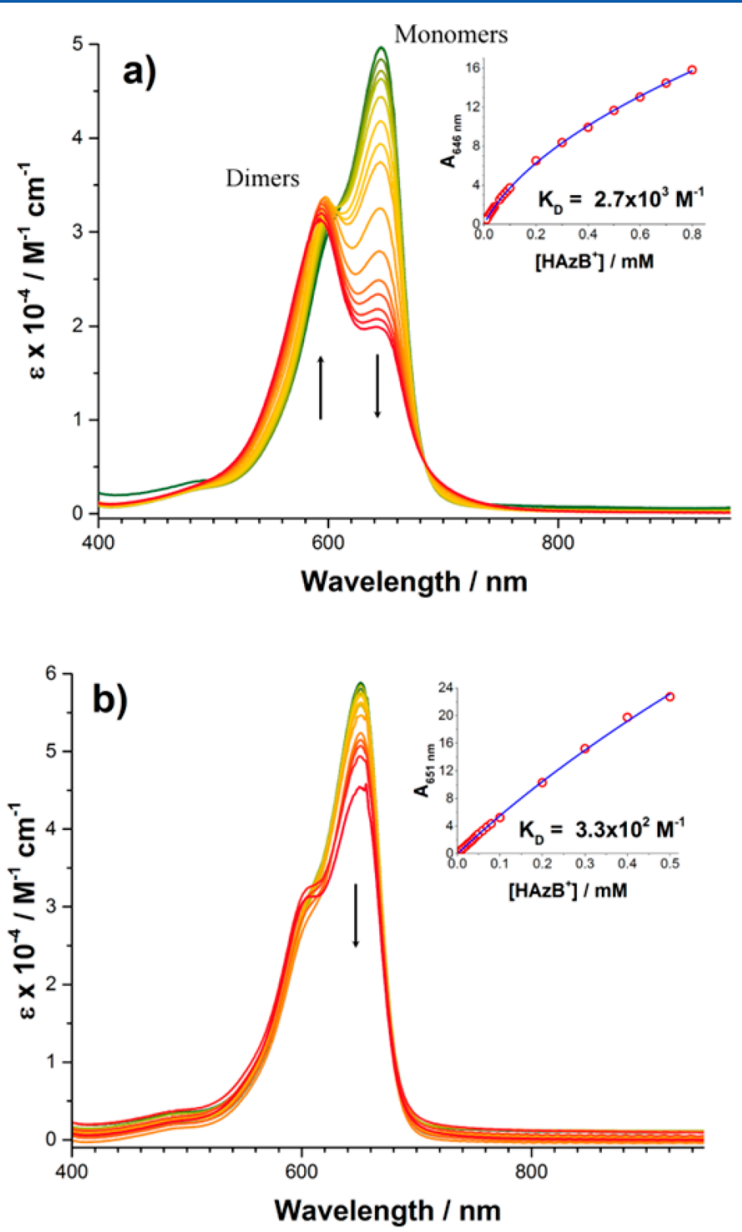

Figure 2. Molar extinction coefficient for $\mathrm{HAzB}^{+}$obtained (a) in the absence of urea at concentrations of 10 (green), 15, 20, 25, 30, 40, 60, $80,100,200,300,400,500,600,700$, and $800 \mu \mathrm{M}$ (red) in water and (b) in the presence of $8 \mathrm{M}$ urea at concentrations of $\mathrm{HAzB}^{+}$of 5 (green), 10, 15, 20, 25, 30, 40, 50, 60, 80, 100, 200, 300, 400, and 500 $\mu \mathrm{M}$ (red). Insets: fittings of the absorbance values at $646 \mathrm{~nm}$ (a) and $651 \mathrm{~nm}(\mathrm{~b})$ as a function of $\left[\mathrm{HAzB}^{+}\right]$. Arrow shows the effect of increasing concentration.

Azure B shows a linear region in the concentration range between 0 and ca. $50 \mu \mathrm{M}$. Beyond this concentration, dimerization of $\mathrm{HAzB}^{+}$is expected to occur (eq 1).

$$
2 \mathrm{HAzB}^{+} \stackrel{K_{\mathrm{D}}}{\rightleftarrows}[\mathrm{HAzB}]_{2}^{2+}
$$

As mentioned above, in an ideal photoionic cell, it is highly desirable to have large amounts of dye dissolved in the aqueous environment. Nonetheless, the data presented in Figure 2 clearly show that aggregation becomes significant at concentrations above $0.2 \mathrm{mM}$, as the extinction coefficient decreases as a function of concentration and the maximum of absorption shifts to blue, below $600 \mathrm{~nm}$.

It is well-known that aggregation of molecules is affected by the presence of chaotropic or chalcotropic agents. ${ }^{13}$ Chaotropic agents like urea ${ }^{14,15}$ can be used to enhance the solubility of the dyes and decrease the degree of aggregation. In order to clarify the effect that these aggregates could have on the overall absorption, urea was added to the reaction medium. The dimerization constant was calculated for both the presence and absence of $8 \mathrm{M}$ urea (see Supporting Information (SI) for further details), revealing that $K_{\mathrm{D}}$ under these conditions falls by 1 order of magnitude from $27 \times 10^{2}$ to $3.3 \times 10^{2} \mathrm{M}^{-1}$. The latter translates into a significant reduction of aggregates such that even at concentrations as high as $0.8 \mathrm{mM} 72 \%$ of the dye is present in its monomeric form (see SI). Similar behavior has been previously reported for thionine, Azure A, and methylene blue. ${ }^{16}$ Additionally, the addition of $8 \mathrm{M}$ urea increases the relative permittivity of the solvent from 78.5 to $96.6^{17}$ and changes the structure of water. The maximum of absorbance of Azure B is also shifted from 646 to $651 \mathrm{~nm}$; similar behavior has been observed before for methylene blue. ${ }^{18}$

To understand how to maximize the system performance, we have to understand the photophysical and physicochemical behavior of the chromophore. The reaction cycle is shown in Scheme 1 . The dye is first excited to the singlet state, followed

\section{Scheme 1. Sequence of Reactions Leading to the Photosensitized Production of Co ${ }^{\mathrm{III}}$ (EDTA) in Water and $\mathrm{H}_{2} \mathrm{AzB}$ in Organic Media (DCE)}

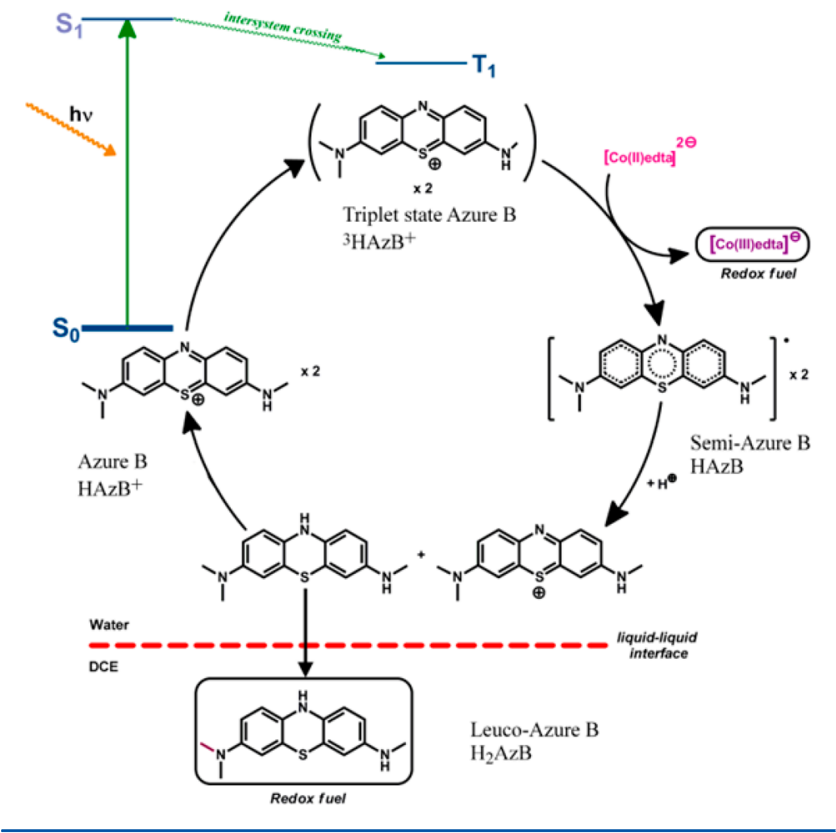

by fast intersystem crossing to the triplet state (lifetime in the order of tens of microseconds, vide infra). The triplet state is quenched by $\mathrm{Co}(\mathrm{II}) \mathrm{EDTA}^{2-}{ }^{2}$, producing Semi-Azure B. The photoproduct undergoes fast disproportionation producing Azure B and neutral Leuco-Azure B that can be extracted into the organic phase.

Another critical parameter for the performance of the photoionic cell is the excited-state lifetime. ${ }^{1}$ For this reason, transient absorption experiments were carried out at various concentrations of $\mathrm{HAzB}^{+}$, and the results are summarized in Table 1. The recorded transient absorption spectra of the triplet states (see SI) agreed well with the previously reported spectra, but the obtained lifetimes were lower. ${ }^{19}$ Consistent with previous studies, ${ }^{19}$ longer lifetimes $(19 \mu$ s at $\mathrm{pH} 8.0)$ were observed for a $\mathrm{pH}$ higher than the $\mathrm{p} K_{\mathrm{a}}$ of the triplet state, which corresponds to 7.2. At pH 5 the lifetime decreased to $5 \mu$ s (see Table 1 and SI). Hence, protonation of the triplet state has a detrimental effect on the lifetime.

According to Table 1, the excited-state lifetime of the dye is significantly reduced as the concentration of aggregates 
Table 1. Lifetimes of Triplet States of $\mathrm{HAzB}^{+}$under $\mathrm{N}_{2}$ at Various Concentrations at pH $8(20 \mathrm{mM}$ Tris/ $\mathrm{HCl}$ buffer $)$ and pH 5 (20 mM Acetate Buffer)

\begin{tabular}{|c|c|c|c|}
\hline & & {$[$ urea $]=0$} & [urea] $=8 \mathrm{M}$ \\
\hline $\mathrm{pH}$ & {$\left[\mathrm{HAzB}^{+}\right] / \mu \mathrm{M}$} & $\tau / \mu \mathrm{s}$ & $\tau / \mu \mathrm{s}$ \\
\hline \multirow[t]{7}{*}{8.0} & 6.2 & 19 & - \\
\hline & 12.5 & 18 & - \\
\hline & 25 & 18 & - \\
\hline & 50 & 17 & - \\
\hline & 100 & 18 & - \\
\hline & 255 & 13 & 20 \\
\hline & 500 & 11 & 19 \\
\hline 5.0 & 6.5 & 5 & - \\
\hline
\end{tabular}

increases (from $200 \mu \mathrm{M}$ ). The latter is not only consistent with the reduced $\Phi$ values obtained at $\left[\mathrm{HAzB}^{+}\right]>0.5 \mathrm{mM}$ (see Figure 4) but also provides a solid basis for the utilization of chaotropic agents that avoid the formation of aggregates to maximize the efficiency of the photosensitized reaction. Thus, in the presence of urea, even at $\left[\mathrm{HAzB}^{+}\right]$as high as $0.5 \mathrm{mM}$, lifetimes similar to those obtained at $\left[\mathrm{HAzB}^{+}\right]$below $50 \mu \mathrm{M}$ are observed.

A third important parameter for the photoionic cell performance is the partition coefficient of the reduced dye. For $\mathrm{H}_{2} \mathrm{AzB}$, the partition coefficient between DCE and the $\mathrm{pH}$ 8 aqueous phase was determined as 6.1. This value is slightly smaller than the value determined for leucothionine with the same method, 14.1. ${ }^{1}$

Electrochemical Characterization. A crucial parameter in the performance of a photoionic cell is the driving force for the electron transfer reaction. For this reason, the electrochemical reduction of Azure $\mathrm{B}$ at various $\mathrm{pH}$ values was carried out. Cyclic voltammograms of $\mathrm{HAzB}^{+}$(Figure S1, SI) at different $\mathrm{pH}$ values showed the presence of a reversible reduction wave at all $\mathrm{pH}$ values tested and corresponds to

$$
\mathrm{HAzB}^{+}+2 e^{-}+\mathrm{H}^{+} \rightarrow \mathrm{H}_{2} \mathrm{AzB}
$$

The number of electrons (2) involved on the reduction of $\mathrm{HAzB}^{+}$was corroborated by means of exhaustive bulk electrolysis. The diffusion coefficient of $\mathrm{HAzB}^{+}$was determined as $4.4 \times 10^{-6} \mathrm{~cm}^{2} \mathrm{~s}^{-1}$ from the scan rate dependency of the peak current (see SI). Values of acidity constants for the deprotonation of $\mathrm{HAzB}^{+}$and its $2 e^{-}$reduction product, $\mathrm{H}_{2} \mathrm{AzB}$, were estimated from the Pourbaix diagram shown in Figure 3. $\mathrm{CV}$ experiments carried out in the presence and in the absence of urea yielded very similar trends, indicating that the acidity constants in the presence of large amounts of the chaotropic agent are not significantly affected. Nonetheless, the voltammograms obtained in the presence of urea were preferred for the determination of the half wave potentials given that the formation of dimers was largely avoided and better defined voltammetric signals were observed at all $\mathrm{pH}$ values (CVs are shown in the SI).

The Pourbaix diagram tells what species is stable in the respective $\mathrm{pH}$ and potential. For reactions involving protons, potential for the reaction calculated from the Nernst equation depends on the activity of protons (when activities of other species stay constant), i.e., $\mathrm{pH}$, by $-a \times 0.0592 \mathrm{~V} / n \times \mathrm{pH}$, where $a$ is the number of protons and $n$ is the number of electrons involved in the reaction. The blue line in the Pourbaix diagram represents the equilibrium $\mathrm{HAzB}^{+}+2 e^{-}+2 \mathrm{H}^{+} \rightarrow$ $\mathrm{H}_{3} \mathrm{AzB}^{+}$. As this reaction includes two protons and two

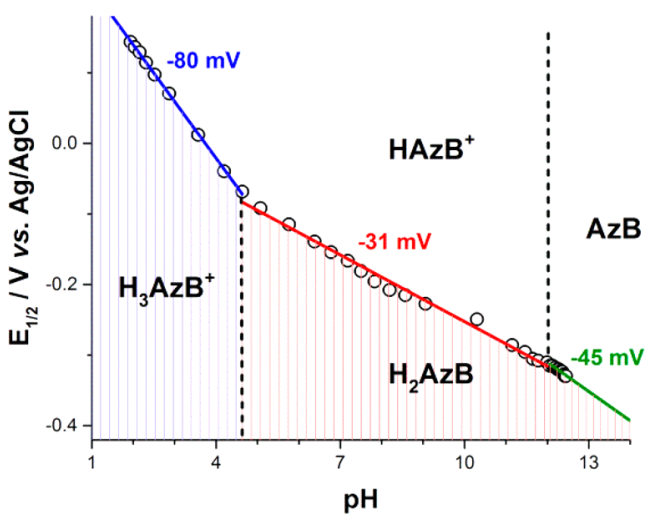

Figure 3. Pourbaix diagram obtained for $\mathrm{HAzB}^{+}$based on $E_{1 / 2}$ values obtained from cyclic voltammograms of a $50 \mu \mathrm{M}$ aqueous solution of $\mathrm{HAzB}^{+}$containing $70 \mathrm{mM} \mathrm{HCl}, 15 \mathrm{mM} \mathrm{CH}{ }_{3} \mathrm{COOH}$, and $15 \mathrm{mM}$ $\mathrm{H}_{3} \mathrm{PO}_{4}$. Progressive $\mathrm{pH}$ changes were obtained by consecutive additions of $25 \mu \mathrm{L}$ of $\mathrm{NaOH} 1.5 \mathrm{M}$.

electrons, the theoretical slope is $59 \mathrm{mV}$. For the red line the reaction 2 includes one proton and two electrons, giving a theoretical slope of $-29.5 \mathrm{mV}$. For the green part, the equilibrium is between $\mathrm{AzB}+2 e^{-}+2 \mathrm{H}^{+} \rightarrow \mathrm{H}_{2} \mathrm{AzB}$, so the theoretical slope is again $-59 \mathrm{mV}$. The experimental slopes of $-80 \mathrm{mV}$ (blue line) and $-45 \mathrm{mV}$ (green line) differ slightly from the theoretical slope of $-59 \mathrm{mV}$, but the red line has a slope of $-31 \mathrm{mV}$, very close to the expected slope of $-30 \mathrm{mV}$. The differences in the low and high $\mathrm{pH}$ can be due to partial dye aggregation or also slight decomposition at high $\mathrm{pH}$.

For the separation of the reaction products in the photoionic cell, the reduced dye has to be neutral to allow its partition into the organic phase. On the basis of the experimental data obtained from the electrochemical Pourbaix diagram in Figure 3, Leuco-Azure $\mathrm{B} \mathrm{H}_{2} \mathrm{AzB}$ has a $\mathrm{p} K_{\mathrm{a}}$ at $\mathrm{pH} 4.8$ and Azure $\mathrm{B}$ a $\mathrm{p} K_{\mathrm{a}}$ at 11.5 , so this $\mathrm{pH}$ range for Azure $\mathrm{B}$ goes from ca. 5 to 12 .

It is also important to know the standard ion transfer potential for the transfer of $\mathrm{HAzB}^{+}$ions to be able to control the partition of the cationic species. The ion transfer voltammetry of $\mathrm{HAzB}^{+}$is shown in the SI, and the standard ion transfer potential was determined as $-0.19 \mathrm{~V}$ on the Galvani potential scale. The summary of the behavior of Azure B is presented in Scheme 2.

Quantum Yield Determination. The information about the photophysical and physicochemical properties of the Azure $\mathrm{B}$ allows us to estimate the optimum conditions for the photoreaction. To allow the extraction of the neutral product, the $\mathrm{pH}$ has to be $>4.8$. To maximize the excited-state lifetimes, optimum $\mathrm{pH}$ has to also be above the $\mathrm{p} K_{\mathrm{a}}$ of the triplet state. Additionally, the presence of urea minimizes the aggregation, leading to a better system performance. Hence, the predicted optimum conditions are reached at $\mathrm{pH} 8$ in the presence of urea. As one of the reaction steps is the disproportionation of the photoproduct, Semi-Azure B, sufficiently high concentration of $\mathrm{HAzB}^{+}$is also required.

Determination of the quantum yields $(\Phi)$ for the separation of photoproducts was carried out as described in the experimental section. The expression describing the quantum yield is

$$
\Phi=\frac{2 \times \text { moles of } \mathrm{H}_{2} \mathrm{AzB} \text { produced }}{\text { moles of photons absorbed }}
$$


Scheme 2. Energy-pH Diagram for Azure B*

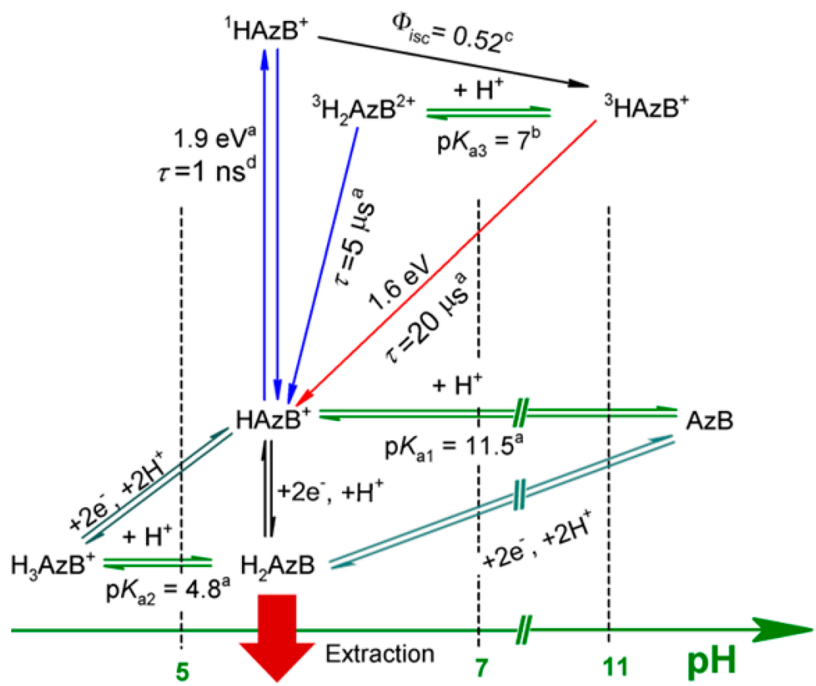

${ }^{* a}$ This work. ${ }^{b}$ Ref $19 .{ }^{c}$ Value for methylene blue at $\mathrm{pH} 7.2$, ref $20 .{ }^{\mathrm{d}}$ Ref 21 . The red arrow indicates the extraction of the neutral dye into the organic phase.

The factor 2 in the equation comes from the fact that two photons are required to produce one molecule of $\mathrm{H}_{2} \mathrm{AzB}$. The effect of the $\mathrm{pH}$ of the aqueous solution on the quantum yield is summarized in Figure $4 \mathrm{a}$ and shows the presence of a maximum quantum yield at $\mathrm{pH} 8$. Lower values below $\mathrm{pH} 6$ are attributed to a less efficient extraction of the reduced dye into the organic phase.

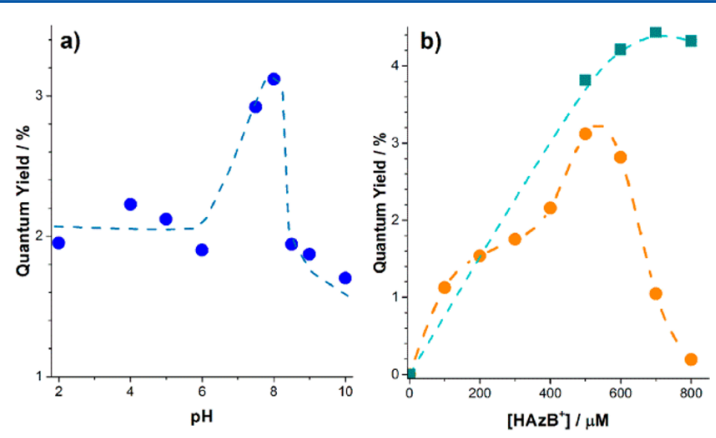

Figure 4. Quantum yields for the consumption of $\mathrm{HAzB}^{+}$in the aqueous phase at $\mathrm{pH} 8$ (Tris/ $\mathrm{HCl}$ buffer $20 \mathrm{mM}$ ) as a function of (a) $\mathrm{pH}$ and (b) concentration of $\mathrm{HAzB}^{+}$in the absence (orange) and in the presence (cyan) of urea $8 \mathrm{M}$.

The latter stems from the protonation of $\mathrm{H}_{2} \mathrm{AzB}$, in accordance with the Pourbaix diagram presented in Figure 3. As the photoproduct is positively charged below $\mathrm{pH}$, extraction into the organic phase does not take place as well as for the neutral product. On the contrary, the equilibrium concentrations of $\mathrm{HAzB}^{+}$and $\mathrm{H}_{3} \mathrm{AzB}^{+}$in both phases will be dictated by the Galvani potential across the water/DCE interface. To ensure that all the $\mathrm{HAzB}^{+}$is available for homogeneous reductive quenching by $\mathrm{Co}$ (EDTA) in the aqueous phase, the Galvani potential was fixed with a common ion, the tetrahexylammonium cation, in both phases. Under the present experimental conditions, the presence of equimolar amounts of $\mathrm{THxA}^{+}$in both phases fixes the potential across the interface at $-0.456 \mathrm{~V}$, calculated as described previously, ${ }^{1,22}$ close to the standard ion transfer potential of $\mathrm{THxA}^{+}$of -0.470
$\mathrm{V}^{23}$ In consequence, hydrophobic cations like $\mathrm{HAzB}^{+}$and $\mathrm{H}_{3} \mathrm{AzB}^{+}$present in the aqueous phase will be more likely to remain there than to transfer into DCE. Unfortunately, the protonated Leuco-Azure $\mathrm{B}\left(\mathrm{H}_{3} \mathrm{AzB}^{+}\right)$present at $\mathrm{pH}$ below 5 remains in the aqueous phase and is therefore more available for back-electron transfer reactions.

The reason for the monotonic decrease in $\Phi$ at $\mathrm{pH}$ values above 8 is at the moment unclear but could be related to the decreased stability of the Co-EDTA complex in alkaline conditions, showing a maximum at ca. $\mathrm{pH} 9$, and EDTA has the fourth $\mathrm{pK} K_{\mathrm{a}}$ at 10.3 . $^{24}$ To our knowledge, the behavior of CoEDTA complexes in alkaline solutions has not been studied in detail. On the other hand, the dependence of $\Phi$ on the total concentration was explored at $\mathrm{pH} 8$ in the absence and in the presence of urea (Figure $2 \mathrm{~b}$ ). In the absence of the chaotropic agent, a steady increase in the quantum yield with the concentration of $\mathrm{HAzB}^{+}$is observed, reaching a maximum at ca. $0.5 \mathrm{mM}$, and is clearly due to an increased concentration of the triplet state ${ }^{3} \mathrm{HAzB}^{+}$. A subsequent decrease in $\Phi$ as the concentration of the dye is further increased is mainly caused by a higher amount of aggregates in the reaction medium. Indeed, according to the $K_{\mathrm{D}}$ value previously determined in the absence of urea, at concentrations above $0.4 \mathrm{mM}$, more than $50 \%$ of the dye is present as aggregates. Aggregation induces splitting of the excited-state levels, offering new pathways for excited states to decay. This is reflected by a reduced lifetime of the triplet state as mentioned previously (Table 1) and therefore inhibits the quenching by $\mathrm{Co}$ (II)EDTA. Aggregation of Azure B could also prevent the encounter with Co(II)EDTA for steric reasons. Confirmation of the negative effect of aggregation on the efficiency of the reaction was obtained from experiments where urea was present in large concentrations (Figure $2 \mathrm{~b}, \mathrm{cyan}$ ). As can be seen from these experiments, $\Phi$ keeps on increasing above $0.5 \mathrm{mM}$ and reaches a steady state value beyond $0.6 \mathrm{mM}$.

The plateau observed in the presence of urea is due to the ratio between $\mathrm{HAzB}^{+}$and $[\mathrm{Co}(\mathrm{II}) \mathrm{EDTA}]^{2-}$. Support for this hypothesis is obtained from additional experiments in which the concentration of the dye was increased to $3 \mathrm{mM}$ and the concentration of the quencher to $1.6 \mathrm{M}$ and a significantly higher $\Phi$ value of $13.1 \%$ was obtained. To the best of our knowledge, this is the highest quantum yield reported for the separation of photoproducts into two immiscible electrolyte solutions. It is also worth noting that the effects of light scattering and dispersion from the cell and from the droplets are not considered, so the true quantum yields are slightly higher. These experiments confirm the predictions made based on photophysical and physicochemical properties of Azure B, highlighting the importance of a thorough characterization of dye properties for development of better systems.

Flow Conditions. A parameter that plays a major role in the kinetics of the reaction is the interfacial area. For this reason, all the quantum yield measurements were carried out under vigorous stirring. Nonetheless, with the long-term goal of interfacing this type of system with a biphasic redox-flow cell, the rate of disappearance of the dye was determined under flow conditions, where the aqueous solution was continuously recirculated in a closed system. As described in the Experimental Section, the aqueous solution was drawn out of the reaction vessel, passed through a UV-vis flow cell, and reinjected into the transparent vessel through a capillary, creating a fine mist of aqueous droplets containing the dye and quencher. A typical spectral sequence and absorbance traces as 
a function of time are presented in Figure 5, where a monotonic decrease in the absorbance at $646 \mathrm{~nm}$ can be observed. A faster
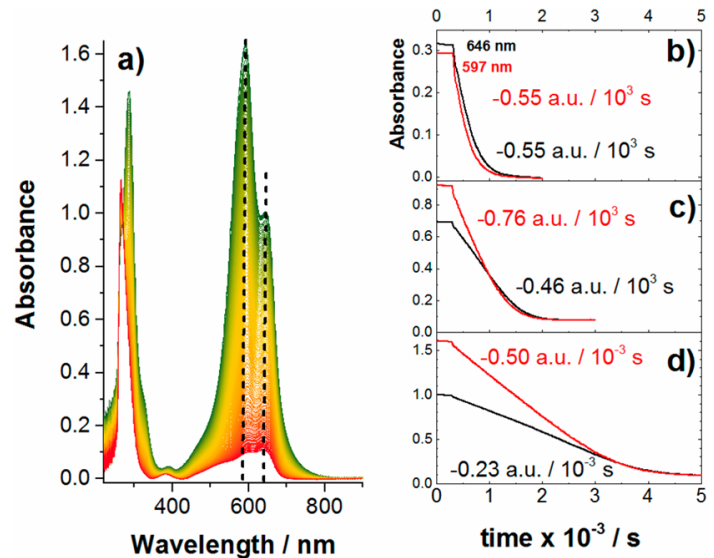

Figure 5. (a) UV-visible spectra acquired every $30 \mathrm{~s}$ upon illumination of fine mist of aqueous droplets containing $20 \mathrm{mM}$ Tris/ $\mathrm{HCl}$ solution $(\mathrm{pH}=8,15 \mathrm{~mL}), \mathrm{HAzB}^{+} 600 \mu \mathrm{M},\left[\mathrm{Co}^{\mathrm{II}} \mathrm{EDTA}\right]^{2-}$ $0.8 \mathrm{M}$, and $\mathrm{THxA}^{+} \mathrm{Cl}^{-} 20 \mathrm{mM}$. Droplets were produced by injecting the aqueous phase at a rate of $4 \mathrm{~mL} / \mathrm{min}$ through a capillary inmmersed in DCE $(25 \mathrm{~mL})$ containing $\mathrm{THxA}^{+} \mathrm{BF}_{4}^{-} 20 \mathrm{mM}$. Absorbance values at 646 (black) and 597 (red) nm extracted from spectral sequences are presented for experiments where $\left[\mathrm{HAzB}^{+}\right]$was 100 (b), 300 (c), and 600 (d) $\mu \mathrm{M}$, with the slopes of the linear parts of the curves.

rate of disappearance of dimers of $\mathrm{HAzB}^{+}$can be observed as dye concentration is increased to $300 \mu \mathrm{M}$. However, when the dye concentration was further increased to $600 \mu \mathrm{M}$, the rate of disappearance of $\mathrm{HAzB}^{+}$decreased again because of the unfavorable effects due to dye aggregation. The rate of monomer consumption decreased with increasing concentration due to the equilibration between dimers and monomers: as monomers were consumed in the photoreaction, dimers dissociated to form more monomers, decreasing the total rate of monomer consumption. Multiple attempts to carry out the reaction under flow conditions in the presence of urea were not successful due to capillary clogging by urea crystals.

As can be observed in Figure 5, photosensitized reactions carried out under flow conditions present a linear decrease in the absorbance over the entire range between 400 and $900 \mathrm{~nm}$. At the same time, this decrease in absorbance is accompanied by the appearance and progressive increase in absorbance of a peak at $270 \mathrm{~nm}$ attributed to $\mathrm{H}_{2} \mathrm{AzB}$ in the aqueous phase. Monitoring of the absorbance as a function of time at the maxima of absorption for the monomeric $(646 \mathrm{~nm})$ and the dimeric $(597 \mathrm{~nm})$ species showed an approximately linear decrease in the absorbance of both species. Nonetheless, at 100 $\mu \mathrm{M}$ (Figure $5 \mathrm{~b}$ ) the absorbance at $646 \mathrm{~nm}$ is always above that at $597 \mathrm{~nm}$ because at this concentration the monomer predominates over the dimeric species. On the contrary, in experiments carried out at higher $\left[\mathrm{HAzB}^{+}\right]$values, e.g., 300 (Figure 5c) and 600 (Figure 5d) $\mu \mathrm{M}$, the absorbance due to the dimeric species is higher than that of the monomer. As the reaction proceeds, however, the absorbance of the monomeric species becomes gradually more important as the total concentration of $\mathrm{HAzB}^{+}$decreases due to the photochemical reaction. This effect can be more easily observed in Figure 5c, where an inversion of the absorbance profiles takes place.
These experimental observations also indicate that under conditions in which droplets of similar sizes are loaded with high concentrations of $\mathrm{HAzB}^{+}$the resulting increased absorbance does not translate into a faster consumption of the dye. On the contrary, the reaction rate is negatively impacted by an increase in $\left[\mathrm{HAzB}^{+}\right]$and further confirms that aggregation is not beneficial to the efficiency of the overall process.

Numerical Simulations. With the aim of identifying the key parameters that affect the efficiency of the reaction under flow conditions, a series of finite element simulations were conducted with COMSOL Multiphysics 4.4. Previously, we have shown that the triplet state lifetime of the oxidized dye and the partition coefficient of the neutral reduced species were the two main parameters affecting the efficiency of the reaction. ${ }^{1}$ In experiments where a fine mist of droplets is produced, however, the size of the droplet plays an important role, in particular in the convective regime produced at the interior of the droplet. Thus, larger droplets will have a higher terminal velocity due to their larger volume compared to smaller droplets. ${ }^{25}$ Empirical and analytical expressions described by Wallis were used to estimate the terminal velocity as a function of droplet radius, with the assumption that the droplet remains spherical. ${ }^{25}$

The previously described model for photoionic cells was extended to study the system where dye and quencher present in a spherical droplet of aqueous phase rises through the organic phase at the terminal velocity. The details of the model are shown in the Supporting Information, and the flow velocity profile for a $1 \mathrm{~mm}$ radius droplet showing the recirculation inside the droplet is shown in Figure 6. The influence of the droplet size on the rate of reaction was quantified by determining the amount of time necessary to consume half of the total amount of oxidized dye in the aqueous droplet (Figure 6 ). The simulations showed the presence of a maximum halflife time at a droplet radius of ca. $300 \mu \mathrm{m}$. Below this size, an approximately linear increase in $t_{1 / 2}$ is observed and is attributed to the longer distance that the neutral product of the photochemical reaction needs to travel in order to be extracted before recombination occurs. Such a monotonic increase is disrupted beyond $300 \mu \mathrm{m}$ droplet size, showing a decrease in $t_{1 / 2}$. To rationalize the simulation results, the flow patterns need to be considered for the different droplet sizes (see SI). Such analysis revealed that the flow pattern is significantly affected at high terminal velocities $(0.05-0.34 \mathrm{~m} /$ $\mathrm{s})$, in the transition region between creeping to laminar flow conditions. Thus, at higher terminal velocities, the velocity at the boundary of the aqueous droplet and surrounding organic phase increases the convection and hence the mass transport inside the droplet. As a result, the residence time for the neutral species produced is significantly shortened causing a net decrease in $t_{1 / 2}$. However, simulations especially at higher terminal velocities are oversimplifications due to the deformations of the droplet. Additionally, surface active species can disrupt the recirculation in the droplet by forming a stagnant cap at the bottom of the droplet, further complicating the mass transport. ${ }^{26}$

Nonetheless, in spite of these limitations, the simulations show that a small droplet size is desirable as small droplets display the fastest reaction times. Additionally, the losses due to recombination were found to be larger in larger droplets (see SI for details). At the given simulation parameters, $10 \mu \mathrm{m}$ radius droplets displayed quantum yields of $45 \%$ (defined as amount 

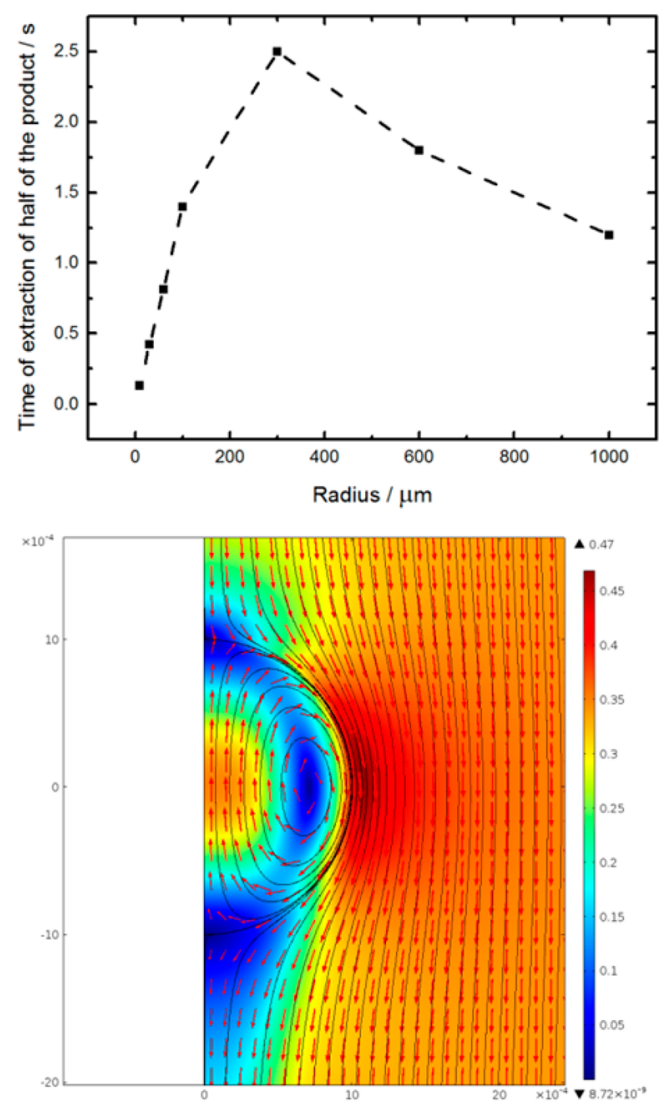

Figure 6. Calculated half-life time of the oxidized dye in the aqueous phase as a function of the aqueous droplet radius. The simulated flow profile is shown below for a $1 \mathrm{~mm}$ radius droplet in a flow of terminal velocity of $0.34 \mathrm{~m} / \mathrm{s}$.

of photoproducts divided by the number of absorbed photons), while a value of only $3.3 \%$ was observed for $300 \mu \mathrm{m}$ radius droplets. On the other hand, small droplets absorb only a small part of the incoming light, so a large number of droplets are required to utilize all the incoming light.

In contrast, the effect of the excited-state lifetime to the photoreaction performance was found to be minimal, due to the fast mass transport (see SI). Practically no difference in the simulations was observed with the excited-state lifetimes of 40 , 18 , and $5 \mu \mathrm{s}$. Decreasing the lifetime below $1 \mu \mathrm{s}$ had a small effect, but the performance of dyes with the excited-state lifetime of $0.5 \mu$ s would still be satisfactory, allowing the use of a larger class of dyes.

\section{CONCLUSIONS}

The photophysical behavior of Azure B has been characterized to optimize the photoreaction performance of photoionic cells. Transient absorption measurements show clearly that the protonation has a detrimental effect on the lifetime of the triplet state. The lifetime is also strongly decreased by the formation of dye aggregates. Nonetheless, this limitation can be overcome by the addition of chaotropic agents like urea, as demonstrated by both UV-vis spectroscopy and transient absorption experiments.

The optimum conditions for the photoreaction could be predicted based on the photophysical and physicochemical properties of the dye. Maximum quantum yield was observed at $\mathrm{pH} 8$ in the presence of $8 \mathrm{M}$ urea. The value of $13.1 \%$ was obtained with a high concentration of quencher, while experiments with a flow system demonstrated the capability of photoionic cells for storing energy in different phases. In paraller, numerical simulations predict that small droplets are preferable in the photocharging stage and will lead to further optimization of the photoionic cells concomitantly with the investigation of alternative dyes with solubilities of more than $0.1 \mathrm{M}$ and low aggregation constants. Additional focus is also required to study the effect of the redox quencher.

This paper highlights the importance of the characterization of dyes, as optimization of conditions can lead to more than one order of magnitude gains in the quantum yield. The results clearly show that addition of chaotropic agents like urea is essential to obtain reasonable performance, as the increased disordering of the water structure significantly reduces aggregation of the chromophores, leading to improved system performance.

\section{ASSOCIATED CONTENT}

\section{S Supporting Information}

Cyclic voltammetry and ion transfer voltammetry, transient absorption results, theory for light absorption of monomers and dimers, finite element simulation model description, and results. This material is available free of charge via the Internet at http://pubs.acs.org.

\section{AUTHOR INFORMATION}

\section{Corresponding Author}

*E-mail: hubert.girault@epfl.ch.

\section{Notes}

The authors declare no competing financial interest.

\section{ACKNOWLEDGMENTS}

The financial support from EPFL and Swiss Federal Office of Energy (SFOE) is gratefully acknowledged.

\section{REFERENCES}

(1) Méndez, M. A.; Peljo, P.; Scanlon, M. D.; Vrubel, H.; Girault, H. H. Photo-Ionic Cells: Two Solutions to Store Solar Energy and Generate Electricity on Demand. J. Phys. Chem. C 2014, 118, 1687216883.

(2) Rabinowitch, E. The Photogalvanic Effect Ii. The Photogalvanic Properties of the Thionine-Iron System. J. Chem. Phys. 1940, 8, 560566.

(3) Rabinowitch, E. The Photogalvanic Effect I. The Photochemical Properties of the Thionine-Iron System. J. Chem. Phys. 1940, 8, 551559.

(4) Mathai, K. G.; Rabinowitch, E. Studies of Thionine-Ferrous Iron Reaction Ina a Heterogeneous System. J. Phys. Chem. 1962, 66, 663664.

(5) Srinivasan, V.; Rabinowitch, E. Photochemical Reduction of Thionine by Cobalt (Ii) Edta Complex in Water-Ether Emulsion. J. Chem. Phys. 1970, 52, 1165-1168.

(6) Albery, W. J.; Archer, M. D. Optimum Efficiency of Photogalvanic Cells for Solar Energy Conversion. Nature 1977, 270, 399402.

(7) Albery, W. J.; Archer, M. D. Photogalvanic Cells: Part 3. The Maximum Power Obtainable from a Thin Layer Photogalvanic Concentration Cell with Identical Electrodes. J. Electroanal. Chem. 1978, 86, 1-18.

(8) Albery, W. J.; Bartlett, P. N.; Foulds, A. W.; Souto-Bachiller, F. A.; Whiteside, R. Photogalvanic Cells. Part 14. The Synthesis and Characterization of Disulphonated Thionines. J. Chem. Soc., Perkin Trans. 2 1981, 794-800.

(9) Albery, W. J. Development of Photogalvanic Cells for Solar Energy Conservation. Acc. Chem. Res. 1982, 15, 142-148. 
(10) Dwyer, F. P.; Gyarfas, E. C.; Mellor, D. P. The Resolution and Racemization of Potassium Ethylenediaminetetra-Acetatocobaltate(Iii). J. Phys. Chem. 1955, 59, 296-297.

(11) Fermin, D. J.; Dung Duong, H.; Ding, Z.; Brevet, P. F.; Girault, H. H. Photoinduced Electron Transfer at Liquid/Liquid Interfaces Part Ii. A Study of the Electron Transfer and Recombination Dynamics by Intensity Modulated Photocurrent Spectroscopy (Imps). Phys. Chem. Chem. Phys. 1999, 1, 1461-1467.

(12) Wandlowski, T.; Mareček, V.; Samec, Z. Galvani Potential Scales for Water-Nitrobenzene and Water-1,2-Dichloroethane Interfaces. Electrochim. Acta 1990, 35, 1173-1175.

(13) Moelbert, S.; Normand, B.; De Los Rios, P. Kosmotropes and Chaotropes: Modelling Preferential Exclusion, Binding and Aggregate Stability. Biophys. Chem. 2004, 112, 45-57.

(14) Mukerjee, P.; Ghosh, A. K. The Effect of Urea on Methylene Blue, Its Self-Association, and Interaction with Polyelectrolytes in Aqueous Solution. J. Phys. Chem. 1963, 67, 193-197.

(15) Hamlin, J. D.; Phillips, D. A. S.; Whiting, A. Uv/Visible Spectroscopic Studies of the Effects of Common Salt and Urea Upon Reactive Dye Solutions. Dyes Pigm. 1999, 41, 137-142.

(16) Ghanadzadeh Gilani, A.; Ghorbanpour, T.; Salmanpour, M. Additive Effect on the Dimer Formation of Thiazine Dyes. J. Mol. Liq. 2013, 177, 273-282.

(17) Wyman, J. Dielectric Constants: Ethanol-Diethyl Ether and Urea-Water Solutions between 0 and $50^{\circ}$. J. Am. Chem. Soc. 1933, 55, 4116-4121.

(18) Patil, K.; Pawar, R; Talap, P. Self-Aggregation of Methylene Blue in Aqueous Medium and Aqueous Solutions of Bu4nbr and Urea. Phys. Chem. Chem. Phys. 2000, 2, 4313-4317.

(19) Havelcová, M.; Kubát, P.; Němcová, I. Photophysical Properties of Thiazine Dyes in Aqueous Solution and in Micelles. Dyes Pigm. 1999, 44, 49-54.

(20) Nemoto, M.; Kokubun, H.; Koizumi, M. Determination of S*-T Transition Probabilities of Some Xanthene and Thiazine Dyes on the Basis of T-Energy Transfer. ii. Results in the Aqueous Solution. Bull. Chem. Soc. Jpn. 1969, 42, 2464-2470.

(21) Moreira, L. M.; Lyon, J. P.; Romani, A. P.; Severino, D.; Rodrigues, M. R.; de Oliveira, H. P. M. Phenotiazinium Dyes as Photosensitizers (Ps) in Photodynamic Therapy (Pdt): Spectroscopic Properties and Photochemical Mechanisms. In Advanced Aspects of Spectroscopy; Farrukh, M. A., Ed.; InTech: Rijeka, Croatia, 2012; pp 393-422.

(22) Kakiuchi, T. Partition Equilibrium of Ionic Components in Two Immiscible Electrolyte Solutions. In Liquid-Liquid Interfaces, Theory and Methods; Volkov, A. G., Deamer, D. W., Eds.; CRC Press: Boca Raton, 1996; pp 1-18.

(23) Olaya, A. J.; Méndez, M. A.; Cortes-Salazar, F.; Girault, H. H. Voltammetric Determination of Extreme Standard Gibbs Ion Transfer Energy. J. Electroanal. Chem. 2010, 644, 60-66.

(24) Zhou, W.; Shao, Z.; Jin, W. Synthesis of Nanocrystalline Conducting Composite Oxides Based on a Non-Ion Selective Combined Complexing Process for Functional Applications. J. Alloys Compd. 2006, 426, 368-374.

(25) Wallis, G. B. The Terminal Speed of Single Drops or Bubbles in an Infinite Medium. Int. J. Multiphase Flow 1974, 1, 491-511.

(26) Sadhal, S. S.; Johnson, R. E. Stokes Flow Past Bubbles and Drops Partially Coated with Thin Films. Part 1. Stagnant Cap of Surfactant Film - Exact Solution. J. Fluid Mech. 1983, 126, 237-250. 